\title{
LA PROTECCIÓN DEL DERECHO A LA IDENTIDAD DE GÉNERO DE LAS PERSONAS TRANS EN EL ORDENAMIENTO JURÍDICO PERUANO DESDE UNA MIRADA DIALÓGICA ENTRE EL DERECHO CONSTITUCIONAL Y EL DERECHO INTERNACIONAL DE LOS DERECHOS HUMANOS: AVANCES, RETROCESOS Y DESAFÍOS
} (2014-2018)

\author{
PROTECTING A TRANSGENDER PERSON'S RIGHT TO GENDER \\ IDENTITY IN THE PERUVIAN LEGAL SYSTEM: FROM A \\ DIALOGICAL PERSPECTIVE BETWEEN CONSTITUTIONAL LAW AND \\ INTERNATIONAL HUMAN RIGHTS LAW: ADVANCES, SETBACKS, AND \\ CHALLENGES (2014-2018)
}

\section{Resumen}

Rafael Rodríguez Campos ${ }^{1}$

En 2014, a través de la Sentencia N ${ }^{\circ}$ 00139-2013-PA/TC, el Tribunal Constitucional (en adelante, Tribunal) estableció como doctrina constitucional que el sexo era un elemento inmutable y que, consecuentemente, no era viable solicitar su modificación en los documentos de identidad. Además, asoció su razonamiento con la idea de que cualquier alteración de la identidad en función de ese criterio debía ser entendida como un "trastorno y/o patología". En otras palabras, para ese Tribunal (Urviola Hani, Vergara Gotelli, Calle Hayen y Alvarez Miranda, fueron los magistrados que votaron en mayoría) las personas transexuales eran "transtornadas o enfermas".

Sin embargo, en una decisión histórica para las personas trans en el Perú, el actual Tribunal (Miranda Canales, Ledesma Narváez, Ramos Nuñez y Espinosa-Saldaña Barrera, fueron los magistrados que votaron en mayoría), emitió la Sentencia $\mathrm{N}^{\circ}$ 06040-2015-PA/TC, mediante la cual se alejó de la doctrina constitucional que había fijado en la sentencia anterior, garantizando el derecho de acceso a la justicia de las personas trans que deseen solicitar la modificación de sus datos en sus documentos de identidad. Es decir, a partir de esta sentencia, el Tribunal reconoce la competencia de los jueces para tutelar el derecho a la identidad y a la personalidad jurídica de las personas trans, ya que considera que "ya no existe ningún impedimento, ni legal, ni jurisprudencial, para garantizar estos derechos".

Palabras Clave: Derecho a la identidad de género, persona trans, Tribunal Constitucional.

Abogado por la Pontificia Universidad Católica del Perú (PUCP). Especialista en Justicia Constitucional, Interpretación y Aplicación de la Constitución en la Universidad Castilla - La Mancha (Toledo - España) 


\section{Abstract}

In 2014, through Ruling No. 00139-2013-PA/TC, the Constitutional Court (hereinafter, Court) established a constitutional precedent whereby gender is an immutable element and, consequently, it is not possible to request any amendment of data in identity documents. In addition, the Court based its reasoning on the idea that any alteration of identity following that criterion should be construed as a "disorder and/or pathology". In other words, for this Court (Urviola Hani, Vergara Gotelli, Calle Hayen and Alvarez Miranda, judges who voted in the majority), transsexual persons were "disturbed or sick".

However, in a landmark decision for transgender persons in Peru, the current Court (Miranda Canales, Ledesma Narváez, Ramos Nuñez and Espinosa-Saldaña Barrera, judges who voted in the majority) issued Ruling No. 06040-2015-PA/TC, by which it strayed away from the constitutional precedent it had set in the previous judgment, guaranteeing the right of access to justice to transgender persons who wish to request the their personal data be updated in their identity documents. In other words, with this decision, the Court recognizes the competence of judges to protect the right to identity and legal personality of transgender persons, as it considers that "there is no longer any impediment, whether legal or jurisprudential, to protecting these rights".

Keywords: Transgender person's right, gender identity, Constitutional Court of Peru.

\section{ANÁLISIS}

\subsection{Razones constitucionales que justificaron el cambio de doctrina constitucional}

$\mathrm{Al}$ respecto, considero importante exponer las razones por las cuales el Tribunal decidió cambiar de doctrina constitucional: a) Primero, porque el transexualismo no puede entenderse como una patología y/o enfermedad; y b) Segundo, porque existe la posibilidad de que, en ciertos casos, el derecho a la identidad personal faculte a un juez a reconocer el cambio de sexo de las personas trans.

Sobre lo primero, el Tribunal señaló que existen evidencias científicas de que el transexualismo no es una patología y/o enfermedad. En efecto, citando a la American Psychologial Association, organización de prestigio a nivel mundial en este campo, para el Tribunal este enfoque que patologizaba el transexualismo ha sido absolutamente superado. Es más, la propia Organización Mundial de la Salud (OMS) ha anunciado 
que también eliminará su tipificación como enfermedad y/o trastorno. Prueba de ello es que el Grupo de Trabajo sobre la Clasificación de Trastornos Sexuales y Salud Sexual de la misma OMS abandonaría el modelo psicopatológico del transgenerismo en el transcurso de 2018, afirmó el Tribunal en la referida sentencia.

Ahora bien, es importante destacar que mientras llevo a cabo la investigación para la elaboración del presente trabajo, llega la noticia de que la OMSha excluidola transexualidad de su lista de trastornos mentales. Lohahecho en la nueva actualización de la Clasificación Internacional de Enfermedades (CIE) publicada el lunes 18 de junio de 2018, en el que la transexualidad pasa a formar parte de una sección nueva denominada "condiciones relativas a la salud sexual" y a denominarse "incongruencia de género". Hasta ahora formaba parte del epígrafe dedicado a "trastornos de la personalidad y el comportamiento" -en el subcapítulo "trastornos de la identidad de género" ${ }^{2}$.

No obstante lo antes señalado, corresponde advertir que no solo cambia el nombre y la situación en el manual, también la definición, ya que hasta ahora, el CIE-10 calificaba la transexualidad como "un deseo de vivir y ser aceptado como miembro del sexo opuesto, por lo general acompañado de malestar o desacuerdo con el sexo anatómico, y de deseo de someterse a tratamiento quirúrgico u hormonal para hacer que el propio cuerpo concuerde lo más posible con el sexo preferido".

En cambio, ahora la definición -para adultos y adolescentes- será: “Una incongruencia marcada y persistente entre el género experimentado del individuo y el sexo asignado, que a menudo conduce a un deseo de 'transición' para vivir y ser aceptado como una persona del género experimentado a través del tratamiento hormonal, la cirugía u otras prestaciones sanitarias para alinear el cuerpo, tanto como se desee y en la medida de lo posible, con el género experimentado. El diagnóstico no puede asignarse antes del inicio de la pubertad. El comportamiento y las preferencias de género por sí solas no son una base para asignar el diagnóstico" ${ }^{\prime 3}$.

2 Esta actualización, como lo reportan algunos medios de divulgación científica, sustituye a la CIE-10, vigente desde mayo de 1990, año en el que la homosexualidad salió de la lista. Desde entonces se han ido autorizando versiones de esta clasificación cada cierto tiempo, pero la transexualidad siempre ha sido considerada un trastorno en contra de las demandas del colectivo trans, que pide la despatologización de su condición. Se trata, como bien lo recuerdan algunos diarios, de una de las reclamaciones LGTBI más férreas que acaba con la filosofía que subyace en la mayoría de legislaciones del mundo: la transexualidad es una enfermedad que debe ser diagnosticada y necesita tratamiento. Por ello, la OMS ha querido alejarse de esta concepción para reconocerlo como una situación que puede entrar en contacto con los servicios de salud, para lo que crea un nuevo capítulo (Visto el 18 de junio de 2018 en: https:// www.eldiario.es/sociedad/OMS-considerar-transexualidad-enfermedad-incongruencia 0 783572396.html)

3 Ahora bien, conviene precisar que La CIE-11 se presentará en la Asamblea Mundial de la Salud de mayo de 2019 para su adopción por los Estados Miembros, y entrará en vigor el 1 de enero de 2022. Esta presentación, ha especificado la OMS en un comunicado, es un avance que permitirá a los países planificar cómo usar la nueva versión, preparar las traducciones y capacitar a los profesionales de la salud de todo el país. 
Pero volviendo a lo que en su momento señaló el Tribunal, resulta fundamental señalar que este criterio también había sido acogido por diversos tribunales internacionales. Para ello, hace alusión al caso de la Corte Interamericana de Derechos Humanos (en adelante, Corte, ver sentencias emitidas en los casos Atala Riffo y niñas vs Chile; y Ángel Alberto Duque vs Colombia), el Tribunal Europeo de Derechos Humanos (sentencias Van Kuck vs Alemania y Godwin vs Reino Unido); y, a nivel de los organismos internacionales como la Organización de Naciones Unidas (Informe Anual del Alto Comisionado de las Naciones Unidas de 2015). Todas estas instituciones han señalado que el Derecho a la Identidad de Género merece una especial protección en el ámbito del Derecho Internacional de los Derechos Humanos debido a su relación directa con el Derecho a la Vida Privada y al Principio de Igualdad y No Discriminación.

En ese sentido, para el Tribunal el transexualismo debe ser entendido como una disforia de género, mas no como una patología; de acuerdo a la evidencia científica referida, y al criterio asumido por diversos tribunales y organismos internacionales, motivo por el cual resultaba necesario dejar de lado la doctrina constitucional impuesta en $2014^{4}$.

Sobre lo segundo, el Tribunal reconoció que fue un error el haber entendido al sexo como un componente exclusivamente estático, ya que a partir de esa equivocada concepción se les impedía a los jueces analizar los casos en los cuales las personas trans les solicitaban la modificación del sexo en sus documentos de identidad. Así, el Tribunal considera que establecer un contenido pétreo de lo que debe entenderse por el derecho a la identidad personal terminó siendo una barrera para la labor interpretativa de los jueces al momento de evaluar este tipo de solicitudes de cambio de sexo.

Asimismo, el Tribunal reiteró su mea culpa al decir que este error ha sido más notorio cuando, en distintas experiencias a nivel comparado e internacional, el avance ha ido en una línea distinta. Para reforzar su posición, por ejemplo, el Tribunal alude a lo señalado por la Comisión Interamericana de Derechos Humanos: "en el ámbito de sus decisiones íntimas y personales y como parte esencial de su proyecto de vida, las personas pueden estar en un proceso de desarrollo constante y fluctuante, construyéndose a sí mismas en relación con una determinada identidad de género".

Esta toma de posición por parte del Tribunal cobra mayor fuerza si se tiene en cuenta la modificación que ha efectuado la OMS, que constituye un logro para el colectivo LGTBI, que reclama seguir avanzando en la despatologización total de la transexualidad. Esto implicaría que no fuera denominada y definida como "una incongruencia", sino como una expresión de la diversidad humana. 
En otras palabras, el Tribunal acoge la tesis por la cual la "realidad biológica" no debe ser el único elemento determinante para la asignación del sexo, ya que el sexo debe comprenderse a la luz de las realidades sociales, culturales e interpersonales que la propia persona experimenta durante su existencia. Por ende, refiere el Tribunal, no debe siempre ser determinado en función de su genitalidad, pues se estaría cayendo en un determinismo biológico, que reduciría la naturaleza humana a una mera existencia física, y ello obviaría que el ser humano es un ser también psíquico y social.

En esa misma línea, el Tribunal hace dos afirmaciones que resultan fundamentales subrayar: a) Primero, que la modificación del sexo de una persona en el registro civil y en los documentos de identidad no genera afectaciones al interés público, no interfiere con la función registral y no afecta el derecho de sucesiones olas relaciones laborales ni la justicia penal; y b) Segundo, que hay una fuerte tendencia de reconocer que existe un derecho a la Identidad de Género, el cual forma parte del contenido constitucionalmente protegido del derecho a la Identidad Personal. Por este motivo, los jueces deben tener la posibilidad real y efectiva de conocer y resolver las solicitudes de cambio de sexo.

Entonces, en atención a lo antes expuesto, quedó abierto el camino, para que los jueces peruanos, tutelen el derecho a la Identidad de Género de las personas trans permitiendo que las mismas puedan cambiar de sexo y/o nombre en sus documentos registrales (Partida de Nacimiento) y en sus documentos de identidad (Documento Nacional de Identidad), debiéndose tomar en cuenta que "la Partida de Nacimiento es el punto de partida del Documento Nacional de Identidad en el Perú".

\subsection{Los jueces peruanos aplican la nueva doctrina constitucional del Tribunal Constitucional}

$\mathrm{Al}$ respecto, corresponde señalar que luego de la entrada en vigencia de la nueva doctrina constitucional del Tribunal sobre la materia, ya se vienen registrando casos en los cuales los jueces peruanos (en primera instancia), atendiendo a las consideraciones conceptuales expuestas por el Tribunal han declarado fundadas las demandas presentadas por los justiciables (personas trans) ordenándole al Registro Nacional de Identificación y Estado Civil $\left(\right.$ RENIEC) ${ }^{5}$, el cambio de sexo y/o nombre tanto en la Partida de Nacimiento

\footnotetext{
El RENIEC, es un organismo constitucionalmente autónomo.

Artículo $183^{\circ}$.- Registro Nacional de Identificación y Estado Civil

(...) El Registro Nacional de Identificación y Estado Civil tiene a su cargo la inscripción de los nacimientos, matrimonios, divorcios, defunciones, y otros actos que modifican el estado civil. Emite las constancias correspondientes. Prepara y mantiene actualizado el padrón electoral. Proporciona al Jurado Nacional de Elecciones y a la Oficina Nacional de Procesos Electorales la información necesaria para el cumplimiento de sus funciones. Mantiene el registro de identificación de los ciudadanos y emite los documentos que acreditan su identidad. Ejerce las demás funciones que la ley señala.
} 
como en el Documento Nacional de Identidad (DNI); como por ejemplo, la sentencia emitida por el Segundo Juzgado Civil del Módulo Básico de Justicia de Paucarpata de la Corte Superior de Justicia de Arequipa que declaró fundada la demanda interpuesta por el ciudadano A.V.V.G, autorizando el cambio de sexo del demandante ${ }^{6}$.

No obstante lo antes señalado, ha surgido en el Perú una nueva interrogante relacionada con la protección del derecho a la Identidad de Género de las personas trans en el ordenamiento jurídico nacional. Una interrogante que trataré de presentar de manera sencilla formulando la siguiente pregunta: ¿Es posible que las solicitudes de cambio de sexo y/o nombre presentadas por las personas trans -que hasta ahora han sido tramitadas en la vía judicial-, al amparo de la protección de su derecho a la Identidad de Género, sean tramitadas en la vía administrativa ante el RENIEC?

\subsection{El Proyecto de Ley de Identidad de Género en el Perú}

Al respecto, es importante señalar que con fecha 15 de diciembre de 2016, el Grupo Parlamentario Frente Amplio por la Justicia, Vida y Libertad, presentó el Proyecto de Ley $N^{\circ} 790 / 2016$, que propone legislar sobre el Derecho a la Identidad de Género.

En síntesis, el referido Proyecto de Ley básicamente planteaba lo siguiente: "Que las solicitudes de cambio de sexo y/o nombre presentadas por las personas trans fueran tramitadas en la vía administrativa, es decir, ante el RENIEC". Ergo, el Proyecto de Ley busca desjudicializar la atención de este tipo de solicitudes.

Sobre el particular, considero oportuno dar a conocer que con fecha 12 de enero de 2017, mediante OFICIO Nº 00549-2016-2017-CCR/CR, el señor Congresista dela República, Miguel Ángel Torres Morales, quien era el Presidente de la Comisión de Constitución y Reglamento, le solicitó al RENIEC emitir un informe conteniendo una opinión técnica sobre el referido Proyecto de Ley.

Fue así como, mediante OFICIO N ${ }^{\circ} 000051-2017 / J N A C / R E N I E C$, de fecha 05 de julio de 2017, el RENIEC remitió el INFORME № 000012-2017/RRC/JNAC/ GA/RENIEC, de fecha 28 de junio de 2017, mediante el cual analizó el contenido y alcances del referido Proyecto de Ley, señalando básicamente lo siguiente:

Resulta necesario destacar la importancia de un Proyecto de Ley que reconoce expresamente el Derecho a la Identidad de Género. Es más, se

Por razones que resultan inexplicables desde el punto de vista constitucional y/o legal, la Procuraduría Pública del RENIEC, en su oportunidad, decidió interponer un Recurso de Apelación contra esta sentencia. 
trata de una propuesta que recoge expresamente la posición expuesta por el Tribunal Constitucional (Expediente. $\mathrm{N}^{\circ}$ 06040-2015-PA/TC) y por la Corte Interamericana de Derechos Humanos (Caso Karen Atala Riffo y niñas vs Chile; y Caso Ángel Alberto Duque vs Colombia) sobre la necesidad de brindar tutela a las personas en razón de su Identidad de Género y Orientación Sexual.

En esa línea, resulta fundamental entender que el Derecho a la Identidad de Género se encuentra directamente relacionado con un conjunto de derechos fundamentales que lo refuerzan y garantizan recíprocamente, como bien se reconoce y desarrolla en el Proyecto de Ley (Libertad, Igualdad, Salud, Integridad, Educación, entre otros).

Asimismo, se considera sumamente relevante que el Proyecto de Ley incorpore expresamente la denominada "Cláusula de No Discriminación", mediante la cual se señala que "discriminación es cualquier distinción, exclusión, restricción o preferencia, en cualquier ámbito público o privado, que tenga el objetivo o el efecto de anular o limitar el reconocimiento, goce o ejercicio, en condiciones de igualdad de uno o más derechos humanos o libertades fundamentales con razón de la Identidad de Género".

Resulta viable y compatible con la Constitución Politica el que toda persona "mayor de edad" pueda solicitar la adecuación registral de sus datos personales (imagen, pre nombres y sexo) en sede administrativa, en este caso mediante un procedimiento sencillo y gratuito ante el RENIEC, cuando los mismos no coincidan con su Identidad de Género. [Cursivas añadidas]

No obstante lo antes señalado, se considera necesario que la solicitud cuente con un informe psicológico elaborado por profesional o entidad, acreditados por la autoridad competente, que sirva de sustento para que en sede administrativa, en este caso el RENIEC, proceda con la adecuación registral, tomando en consideración el concepto de disforia de género desarrollado por el Tribunal Constitucional en el Expediente antes referido (el subrayado es nuestro). [Cursivas añadidas]

Entonces, queda claro que el RENIEC, organismo constitucionalmente autónomo encargado de registrar la identidad de las personas en el Perú, bajo las consideraciones expuestas en los párrafos precedentes, emitió una opinión favorable con respecto al referido Proyecto de Ley para que las solicitudes de cambio de sexo y/o nombre presentadas por las personas trans puedan ser tramitas en la vía administrativa ${ }^{7}$.

Es oportuno precisar que la opinión remitida por el RENIEC al Congreso de la República es anterior a la publicación de la Opinión Consultiva OC-24/2017 de la Corte Interamericana de Derechos Humanos sobre Identidad de Género, e Igualdad y No Discriminación a parejas del mismo sexo. 
Cabe precisar, que la Defensoría del Pueblo $^{8}$ también se había pronunciado a favor de esta propuesta en setiembre de 2016, mediante la publicación del Informe Defensorial $\mathrm{N}^{\circ} 175$, titulado "Derechos Humanos de las personas LGTBI: Necesidad de una política pública para la igualdad en el Perú", que en la parte Recomendaciones, dirigida al Congreso de la República, señaló en el Punto 1 lo siguiente:

"Aprobar una Ley de Identidad de Género que establezca un procedimiento administrativo a cargo del Registro Nacional de Identificación y Estado Civil (RENIEC) para que las personas trans puedan cambiar su nombre y/o sexo en sus documentos de identidad. Este procedimiento debe ser célere, no patologizante y respetuoso de su dignidad e intimidad" [Cursivas añadidas].

No obstante lo antes expuesto, es lamentable señalar, que a pesar del tiempo transcurrido desde la presentación del referido Proyecto de Ley (15 de diciembre de 2016) hasta la fecha (01 de agosto de 2018), este todavía no haya sido dictaminado, y menos aprobado por la Comisión de Constitución y Reglamento del Parlamento, que es el paso previo para que cualquier Proyecto de Ley sea aprobado por el Congreso de la República, para luego ser publicado en el diario oficial El Peruano, y convertirse en Ley al día siguiente de la misma, según lo dispuesto en el artículo $105^{\circ}$ y $109^{\circ}$, respectivamente, de la Constitución Política.

\subsection{La Opinión Consultiva OC-24/2017 de la Corte Interamericana de Derechos Humanos}

Al respecto, y por el impacto que las decisiones de la Corte Interamericana de Derechos Humanos (en adelante, Corte) tienen para el ordenamiento jurídico peruano, asunto que explicaremos a lo largo de nuestro análisis, es oportuno señalar que el 18 de mayo de 2016, Costa Rica, como Estado Miembro de la Organización de Estados Americanos (en adelante, OEA), presentó ante la Corte, la solicitud de Opinión Consultiva que buscaba que se interprete la protección que brinda la Convención Americana sobre Derechos Humanos (en adelante, la Convención) al reconocimiento del cambio de nombre de las personas, de acuerdo con la Identidad de Género de cada una. Asimismo, Costa Rica también solicitó a la Corte interpretar cuál es la protección que brinda la Convención al reconocimiento de los derechos patrimoniales derivados de un vínculo entre personas del mismo sexo.

\footnotetext{
La Defensoría del Pueblo es un organismo constitucionalmente autónomo.

Artículo 162.- Atribuciones de la Defensoría del Pueblo

(...) Corresponde a la Defensoría del Pueblo defender los derechos constitucionales y fundamentales de la persona y de la comunidad; y supervisar el cumplimiento de los deberes de la administración estatal y la prestación de los servicios públicos a la ciudadanía.
} 
Luego, el 9 de enero de 2018, la Corte publicó el texto de la Opinión Consultiva OC-24/2017 (en adelante, OC 24/17), mediante la cual aborda un conjunto de materias relacionadas con el principio de no discriminación por Identidad de Género y Orientación Sexual ${ }^{9}$, reconociendo lo siguiente: a) El derecho a la Identidad de Género y Orientación Sexual de las personas trans (garantizando procedimientos que posibiliten el cambio de nombre y/o sexo); y 2) La protección convencional de los vínculos de parejas del mismo sexo (incluye el reconocimiento del matrimonio civil para estas parejas), reiterando la línea de razonamiento expuesta en su jurisprudencia en los casos Atala Riffo y niñas vs Chile (2012) y Ángel Alberto Duque vs Colombia (2016), respectivamente.

Sobre lo primero, la Corte ratifica que la Identidad de Género y Orientación Sexual son categorías protegidas por la Convención. Y por tanto, señala que la falta de un consenso al interior de algunos países sobre el respeto pleno por los derechos de ciertos grupos o personas que se distinguen por su orientación sexual, su identidad de género o su expresión de género, reales o percibidas, no puede ser considerado como un argumento válido para negarles o restringirles sus derechos humanos o para perpetuar y reproducir la discriminación histórica y estructural que estos grupos o personas han sufrido.

En esa línea, la Corte define a la Identidad de Género como la vivencia interna e individual del género tal como cada persona la siente, la cual podría corresponder o no con el sexo asignado al momento del nacimiento. Asimismo, afirma que el derecho a la Identidad de Género y Sexual se encuentra ligado al concepto de libertad y la posibilidad de todo ser humano de auto-determinarse y escoger libremente las opciones y circunstancias que le dan sentido a su existencia, conforme sus propias opciones y convicciones. Y por tanto, establece que el reconocimiento de la Identidad de Género por el Estado resulta de vital importancia para garantizar el pleno goce de los derechos humanos de las personas trans.

A partir de ello, la Corte considera que el cambio de nombre, la adecuación de la imagen, así como la rectificación a la mención del sexo o género, en los registros y en los documentos de identidad para que estos sean acordes a la Identidad de Género auto-percibida, es un derecho protegido por la Convención, y por tanto, los Estados están en la obligación de reconocer, regular, y establecer los procedimientos adecuados para tales fines.

Para la resolución de esta solicitud de opinión consultiva, la Corte tomó en cuenta y analizó noventa y uno escritos así como cuarenta participaciones en audiencia para presentar observaciones, e intervenciones recibidas de parte de Estados, órganos de la OEA, organizaciones internacionales, organismos estatales, organizaciones no gubernamentales, instituciones académicas y personas de la sociedad civil. 
Además, la Corte especificó las condiciones mínimas que deben tener estos procedimientos internos. Así, para la Corte estos deben estar destinados a reflejar la identidad de género auto-percibida; deben basarse en un consentimiento libre e informado; no deben exigir certificaciones médicas o psicológicas que resulten irrazonables o patologizantes; deben ser de carácter reservados, deben proteger los datos personales y no reflejar cambios de identidad de género; deben ser expeditos y tender a la gratuidad en la medida de lo posible, y no deben requerir la acreditación de operaciones quirúrgicas y/o tratamientos hormonales.

Adicionalmente, la Corte concluyó que los trámites materialmente administrativos son los que mejor se ajustan a dichos requisitos, y precisó además que ese procedimiento no necesariamente debe ser regulado por ley.

Sobre lo segundo, la Corte ratifica que la Convención no protege un determinado modelo de familia. Debido a que la definición misma de familia no es exclusiva de aquella integrada por parejas heterosexuales. Es decir considera que el vínculo familiar que puede derivar de la relación de una pareja del mismo sexo se encuentra protegido por la Convención.

En esa línea, la Corte considera que todos los derechos patrimoniales que se derivan del vínculo familiar de parejas del mismo sexo deben ser protegidos, sin discriminación alguna con respecto a las parejas entre personas heterosexuales. Pero no sólo eso, ya que la Corte estima que esta obligación internacional de los Estados trasciende a la protección de las cuestiones únicamente patrimoniales y se proyecta a todos los derechos humanos, reconocidos a parejas heterosexuales, tanto internacionalmente como en el derecho interno de cada Estado.

A partir de ello, la Corte sostiene que para garantizar los derechos de las parejas del mismo sexo no es necesaria la creación de nuevas figuras jurídicas, y por ende, opta por extender las instituciones existentes a las parejas compuestas por personas del mismo sexo -incluyendo el matrimonio civil-, en observancia del principio pro persona, y porque además, este constituye el medio más sencillo y eficaz para asegurar los derechos derivados del vínculo entre parejas del mismo sexo.

Ahora bien, sobre el matrimonio civil entre personas del mismo sexo, la Corte señala categóricamente que crear una institución que produzca los mismos efectos y habilite los mismos derechos que el matrimonio, pero que no lleve ese nombre carece de sentido, salvo el de señalar socialmente a las 
parejas del mismo sexo con una denominación que indique una diferencia sino estigmatizante, por lo menos como señal de subestimación. Por esta razón, la Corte considera que no era admisible la existencia de dos clases de uniones solemnes para consolidar jurídicamente la comunidad de convivencia heterosexual y homosexual, ya que configuraría una distinción fundada en la orientación sexual de las personas, que resultaría discriminatoria, y por tanto incompatible con la Convención.

En ese sentido, la Corte reconoce que si bien la oposición al matrimonio de personas del mismo sexo está basada en convicciones religiosas o filosóficas, éstas no pueden ser utilizadas para condicionar lo que la Convención establece respecto de la discriminación en razón de orientación sexual. Más aún, la Corte establece que en sociedades democráticas debe existir coexistencia mutuamente pacífica entre lo secular y lo religioso; por lo que el rol de los Estados y de la Corte, es reconocer la esfera en la cual cada uno de éstos habita y en ningún caso forzar uno en la esfera de otro.

Por lo antes expuesto, la Corte establece que siempre y cuando exista la voluntad de relacionarse de manera permanente y conformar una familia, existe un vínculo que merece igualdad de derechos y protección sin importar la orientación sexual de sus contrayentes. No obstante ello, la Corte precisa que al afirmar esto no le está restando valor a la institución del matrimonio, sino por el contrario, lo estima necesario para reconocerle igual dignidad a personas que pertenecen a un grupo humano que ha sido históricamente oprimido y discriminado.

Por último, la Corte recordó que cuando un Estado es parte de un tratado internacional, como la Convención, dicho tratado obliga a todos sus poderes y organismos (Ejecutivo, Legislativo, Judicial, Tribunal Constitucional, y otros). Por tanto, la Corte considera necesario que los Estados que son parte de la Convención (entre los cuales figura el Perú) impulsen realmente y de buena fe las reformas necesarias para adecuar sus normas, interpretaciones y prácticas internas, aplicando los estándares establecidos en esta OC 24/17

\subsection{La vinculatoriedad de las Opiniones Consultivas de la Corte Interamericana de Derechos Humanos}

Al respecto, es necesario reconocer, que la publicación de la referida OC 24/17 ha sido objeto tanto de celebración como de rechazo en diversos sectores, no sólo de la sociedad de Costa Rica -país que solicitó la opinión- sino 
de toda América Latina. El debate no ha sido ajeno a la comunidad jurídica peruana, en la cual, por ejemplo, podemos encontrar a colegas renuentes a considerar las opiniones consultivas como fuentes de derecho, pues estiman que las mismas se reducen a un mero ejercicio declarativo de la Corte. Siendo ello así, cabría preguntarnos lo siguiente: ¿Son obligatorios los estándares de la OC 24/17 para los países que como el Perú forman parte de la OEA?

En primer lugar, y como lo señala el notable jurista colombiano Jorge Roa (2015), "el hecho de que existan al menos veinte sentencias contenciosas de la Corte, en las que se aplican estrictamente criterios formulados en las opiniones consultivas prueba que al menos la misma Corte entiende que la fuerza horizontal de sus opiniones consultivas es absoluta" [Cursivas añadidas]. (p.107,108)

En segundo lugar, debemos reconocer que la Corte ha señalado reiteradamente que cuando un Estado es parte de un tratado internacional, todos sus órganos -incluyendo a los que forman parte de la Administración Públicatambién están sometidos al tratado (el subrayado es nuestro). En ese sentido, estos órganos estatales, sin distinción alguna, asumen la obligación de velar que los efectos de las disposiciones de la Convención no se vean mermados por la aplicación de normas contrarias a su objeto y fin, y para ello, deben ejercer un control de convencionalidad teniendo en cuenta no solamente el tratado, sino también la interpretación que del mismo ha hecho la Corte (el subrayado es nuestro $)^{10}$.

En tercer lugar, y para comprender el efecto vinculante de la OC 24/17, creo oportuno hacer referencia a lo expuesto por los destacados juristas mexicanos Ángeles Cruz Rosel y Carlos Escoffipe Duarte, quienes en su artículo titulado ¿Es vinculante la opinión consultiva 24/17, sobre derechos LGBTI, de la Corte Interamericana?, señalan que la Corte ha identificado dos manifestaciones de la obligación de ejercer un control de convencionalidad: a) Primero, cuando existe una sentencia internacional con carácter de cosa juzgada y; b) Segundo, "en situaciones y casos" en que el Estado concernido no ha sido parte en el proceso internacional en que fue establecida determinada jurisprudencia, como es el caso del Perú . Ahora, por razones obvias, me centraré en la segunda de estas manifestaciones.

10 Véase, entre otros: Corte IDH. Caso Almonacid Arellano y otros Vs. Chile. Excepciones Preliminares, Fondo, Reparaciones y Costas. Sentencia de 26 de septiembre de 2006. Serie C No. 154, párr. 124; Caso Liakat Ali Alibux Vs. Surinam. Excepciones Preliminares, Fondo, Reparaciones y Costas. Sentencia de 30 de enero de 2014. Serie C No. 276, párr. 124; Caso Fontevecchia y D`Amico Vs. Argentina. Fondo, Reparaciones y Costas. Sentencia de 29 de noviembre de 2011. Serie C No. 238, párr. 93; Caso Mendoza y otros Vs. Argentina. Excepciones Preliminares, Fondo y Reparaciones. Sentencia de 14 de mayo de 2013. Serie C No. 260, párr. 221; y Caso Cabrera García y Montiel Flores Vs. México. Excepción Preliminar, Fondo, Reparaciones y Costas. Sentencia de 26 de noviembre de 2010. Serie C No. 220, párr.79. 
Sobre este punto, los autores referidos destacan que la Corte hace alusión a "situaciones y casos" que establecen jurisprudencia lo cual incluye a las opiniones consultivas (el subrayado es nuestro). De hecho, los autores recuerdan que la Corte expresamente ha señalado que en el ejercicio de su función consultiva no existen "partes" involucradas y no existe tampoco un litigio a resolver, por lo que las opiniones consultivas cumplen la función propia de un control de convencionalidad preventivo ${ }^{11}$.

En cuarto lugar, cabe recordar que la propia Corte ha indicado -por lo menos desde 2013, de manera uniforme y reiterada- que en situaciones en las cuales el Estado no ha sido parte del proceso internacional en que fue establecida determinada jurisprudencia por el sólo hecho de ser parte de la Convención- todas sus autoridades públicas y todos sus órganos deben ejercer, en el marco de sus competencias, el examen de la compatibilidad de sus actuaciones con los estándares interamericanos ${ }^{12}$.

En quinto lugar, y contrario a lo que algunos colegas peruanos han sostenido, queda claro que ese control de convencionalidad también debe ejercerse sobre lo establecido por la Corte en su función consultiva. Así ha quedado claramente establecido por la Corte en su Opinión Consultiva 21/14, al indicar que todos los órganos de los Estados parte de la Convención deben realizar este control incluyendo las interpretaciones realizadas a través de una opinión consultiva. Es más, los colegas peruanos olvidan, por ejemplo, que el propio Tribunal Constitucional ha resuelto casos aplicando estrictamente los criterios establecidos por la Corte en sus opiniones consultivas ${ }^{13}$.

En sexto lugar, la Corte también ha señalado que a partir de la norma convencional interpretada a través de la emisión de una opinión consultiva, todos los órganos de los Estados Miembros de la OEA, incluyendo a los que no son Parte de la Convención pero que se han obligado a respetar los derechos humanos en virtud de la Carta de la OEA (artículo 3.1) y la Carta Democrática Interamericana (artículos 3, 7, 8 y 9), cuentan con una fuente que, acorde a su propia naturaleza, contribuye también y especialmente de manera preventiva, a lograr el eficaz respeto y garantía de los derechos humanos y, en particular, constituye una guía a ser utilizada para resolver

11 Corte IDH. Titularidad de derechos de las personas jurídicas en el sistema interamericano de derechos humanos (Interpretación y alcance del artículo 1.2, en relación con los artículos 1.1, 8, 11.2, 13, 16, 21, 24, 25, 29, 30, 44, 46, y 62.3 de la Convención Americana sobre Derechos Humanos, así como del artículo 8.1 A y B del Protocolo de San Salvador). Opinión Consultiva OC-22/16 de 26 de febrero de 2016. Serie A No. 22, párr. 26.

12 Corte IDH. Caso Gelman Vs. Uruguay. Supervisión de Cumplimiento de Sentencia. Resolución de la Corte Interamericana de Derechos Humanos de 20 de marzo de 2013, párr. 69.

13 STC Exp. N ${ }^{\circ}$ 0027-2005-PI/TC (Opinión Consultiva OC-5/85, La colegiación obligatoria de periodistas (arts. 13 y 29 de la Convención Americana sobre Derechos Humanos), de 13 de noviembre de 1985). 
los casos que se presenten y así evitar eventuales vulneraciones de derechos humanos ${ }^{14}$.

Por último, queda claro, sobre todo para quienes hemos seguido con atención el desarrollo de la jurisprudencia de la Corte, y entendemos la importancia que tiene la relación dialógica entre el Derecho Constitucional y el Derecho Internacional de los Derechos Humanos en el proceso de interpretación y protección de los derechos fundamentales de las personas en los Estados que forman parte de la OEA, que existen argumentos jurídicos suficientes para determinar que las obligaciones contenidas en la OC 24/17 no sólo son vinculantes para el estado de Costa Rica, como algunos colegas pretenden hacernos creer, sino también para países como el Perú, que hasta la fecha no cuentan con procedimientos administrativos que viabilicen el cambio de sexo y/o nombre de las personas trans, en defensa del derecho a la Identidad de Género de estas personas, y con las características que la Corte establece.

Finalmente, siguiendo lo expuesto por los juristas mexicanos antes citados, cabría reformular la pregunta que hiciéramos al iniciar esta parte de nuestro análisis: ¿Existen motivos para no reconocer las obligaciones establecidas en la OC 24/17? ¿Es sincero y honesto, académica y profesionalmente hablando, el debate sobre su carácter vinculante o una simple estrategia para deslegitimar el reconocimiento hecho por la Corte? ¿Qué más pronunciamientos o estándares internacionales en materia de interpretación y protección de derechos humanos necesitan los órganos del Estado (legislativos, jurisdiccionales o administrativos) de nuestros países para que decidan tomar en serio la defensa del derecho a la Identidad de Género, el Derecho a la Igualdad y No Discriminación, de las personas trans?

\subsection{El impacto de la Opinión Consultiva OC-24/2017 en el ordenamiento jurídico peruano}

$\mathrm{Al}$ respecto, es importante señalar -mucho más tomando en consideración lo expuesto en el punto precedente de nuestro análisis- lo que la Constitución Política del Perú establece en la Cuarta Disposición Final y Transitoria sobre la interpretación de los derechos fundamentales:

\section{Cuarta Disposición Final y Transitoria - Interpretación de los derechos fundamentales}

14 Corte IDH. Derechos y garantías de niñas y niños en el contexto de la migración y/o en necesidad de protección internacional. Opinión Consultiva OC-21/14 de 19 de agosto de 2014. Serie A No. 21, párr. 31. 
Las normas relativas a los derechos y a las libertades que la Constitución reconoce se interpretan de conformidad con la Declaración Universal de Derechos Humanos y con los tratados y acuerdos internacionales sobre las mismas materias ratificados por el Perú.

Asimismo, el Código Procesal Constitucional del Perú, aprobado mediante la Ley $\mathrm{N}^{\circ}$ 28237, también sobre la interpretación de los derechos fundamentales, señala en el artículo V de su Título Preliminar lo siguiente:

\section{Artículo V.- Interpretación de los Derechos Constitucionales}

El contenido y alcances de los derechos constitucionales protegidos por los procesos regulados en el presente Código deben interpretarse de conformidad con la Declaración Universal de Derechos Humanos, los tratados sobre derechos humanos, así como de las decisiones adoptadas por los tribunales internacionales sobre derechos humanos constituidos según tratados de los que el Perú es parte.

Entonces, si hablamos del caso concreto, al amparo de ambas disposiciones jurídicas (una constitucional y otra legal), que marcan pautas para la interpretación de los derechos fundamentales, podemos afirmar categóricamente que los jueces peruanos, al momento de interpretar el contenido y alcances del Derecho a la Identidad de Género -en el marco de procesos judiciales en los que personas trans soliciten el cambio de sexo y/o nombre- deberán hacerlo tomando en consideración lo expuesto por la Corte en la referida OC 24/17.

\subsection{El siguiente paso: Desjudicializar el proceso de cambio de sexo y/o nombre de las personas trans en defensa de su derecho a la Identidad de Género}

Al respecto, conviene señalar que luego de la publicación de la mencionada OC 24/17, se ha desatado en el Perú una interesante polémica en torno a la posibilidad de desjudicializar el proceso de cambio de sexo y/o nombre de las personas trans en defensa de su derecho a la Identidad de Género, remitiendo estas solicitudes a la vía administrativa (en el caso peruano, como ya lo señalé, se tramitarían ante el RENIEC).

En ese sentido, creo oportuno recordar lo que la Corte ha dicho al respecto:

A partir de ello, la Corte considera que el cambio de nombre, la adecuación de la imagen, así como la rectificación a la mención del 
sexo o género, en los registros y en los documentos de identidad para que estos sean acordes a la identidad de género auto-percibida, es un derecho protegido por la Convención, y por tanto, los Estados están en la obligación de reconocer, regular, y establecer los procedimientos adecuados para tales fines.

Además, la Corte especificó las condiciones mínimas que deben tener estos procedimientos internos: estos deben estar destinados a reflejar la identidad de género auto-percibida; deben basarse en un consentimiento libre e informado; no deben exigir certificaciones médicas o psicológicas que resulten irrazonables o patologizantes; deben ser de carácter reservados, proteger los datos personales y no reflejar cambios de identidad de género; deben ser expeditos y tender a la gratuidad en la medida de lo posible, y no deben requerir la acreditación de operaciones quirúrgicas y/o hormonales.

Adicionalmente, la Corte concluyó que los trámites materialmente administrativos son los que mejor se ajustan a dichos requisitos, y precisó además que ese procedimiento no necesariamente debe ser regulado por ley.

Sobre el particular, resulta fundamental reiterar lo ya señalado en párrafos precedentes:

Primero, que el Grupo Parlamentario Frente Amplio por la Justicia, Vida y Libertad, presentó el Proyecto de Ley $N^{\circ} 790 / 2016$, que proponía básicamente lo siguiente: "Que las solicitudes de cambio de sexo y/o nombre presentadas por las personas trans fueran tramitadas en la vía administrativa, es decir, ante el RENIEC". Es decir, el Proyecto de Ley busca desjudicializar la atención de este tipo de solicitudes.

Segundo, que el RENIEC, organismo constitucionalmente autónomo encargado de registrar la identidad de las personas en el Perú, emitió una opinión favorable con respecto al referido Proyecto de Ley para que las solicitudes de cambio de sexo y/o nombre presentadas por las personas trans sean tramitadas en la vía administrativa ante dicha institución.

Tercero, que la Defensoría del Pueblo, organismo constitucionalmente autónomo, se ha pronunciado a favor de esta propuesta en setiembre de 2016, mediante la publicación del Informe Defensorial $N^{\circ} 175$, titulado "Derechos Humanos de las personas LGTBI: Necesidad de una política pública para la igualdad en el Perú", que en la parte Recomendaciones $N^{\circ} 1$, dirigida al Congreso de la República, le recomendó lo siguiente: 
Aprobaruna Ley deIdentidad deGéneroqueestablezcaun procedimiento administrativo a cargo del Registro Nacional de Identificación y Estado Civil (RENIEC) para que las personas trans puedan cambiar su nombre y/o sexo en sus documentos de identidad. Este procedimiento debe ser célere, no patologizante y respetuoso de su dignidad e intimidad.

Por último, a propósito de lo señalado por la Corte en cuanto a que los trámites administrativos son los que mejor se ajustan a dichos requisitos, y que ese procedimiento no necesariamente debe ser regulado por ley, es oportuno mencionar que el RENIEC, mediante la Resolución Jefatural $N^{\circ}$ 19-2018/ JNAC/RENIEC, de fecha 14 de febrero de 2018, dispuso la conformación de un Grupo de Trabajo encargado de analizar el contenido y alcances, en todo lo que corresponda, de lo señalado por la Corte en la referida OC 24/17, el mismo que debía emitir un Informe Final (hasta el 14 de mayo de 2018), que servirá como base para la implementación, en caso corresponda, de lo señalado por la Corte en la OC 24/17, incluyendo este último punto.

No obstante lo antes señalado, siguiendo la línea jurisprudencial marcada por la Corte en esta OC 24/17, y tomando como referencia lo expuesto en el punto 2.4 y 2.5, respectivamente, de nuestro análisis, considero que -ante la ausencia de una Ley de Identidad de Género en el Perú- es perfectamente compatible con la Convención y con la Constitución Política del Perú, que el RENIEC, organismo constitucionalmente autónomo del Estado peruano, diseñe y aprueba un procedimiento administrativo para la tramitación de las solicitudes de cambio de sexo y/o nombre de las personas trans en defensa de su Derecho a la Identidad de Género, el mismo que deberá cumplir con las condiciones anotadas en el punto precedente.

Por último, considero necesario señalar que esta medida también encuentra sustento normativo directo en el artículo V del Título Preliminar de la Ley $\mathrm{N}^{\circ}$ 27444, Ley del Procedimiento Administrativo General, que señala, en el numeral 2.1 y 2.2, respectivamente, referidos a las Fuentes del Procedimiento Administrativo, que son fuentes del Procedimiento Administrativo tanto las disposiciones constitucionales como los tratados y convenios internacionales incorporados al Ordenamiento Jurídico Nacional, mención que para el caso de los Tratados Internacionales sobre Derechos Humanos, como la Convención, cobra especial importancia, ya que es necesario recordar que estos tratados tienen rango constitucional, según lo ha reconocido el propio Tribunal Constitucional en la STC $\mathrm{N}^{\circ}$ 047-2004-AI/TC (Fundamento 22). 


\subsection{La Defensoría del Pueblo frente al RENIEC}

Al respecto, considero relevante señalar que la Defensoría del Pueblo, mediante el INFORME DE ADJUNTÍA No 002-2018-DP/ADHPD, elaborado por la Adjuntía para los Derechos Humanos y las Personas con Discapacidad, publicado en mayo de 2018, denominado "Obligación del Estado Peruano de Aplicar los Estándares Internacionales para el Reconocimiento y Protección del Derecho a la Identidad de Género", ha llamado severamente la atención al RENIEC por la decisión de su Procuraduría Pública de interponer un Recurso de Apelación contra la Sentencia Nº 001-2018-CI-2JCP, emitida por el Segundo Juzgado Civil del Módulo Básico de Justicia de Paucarpata de la Corte Superior de Justicia de Arequipa que declaró fundada la demanda interpuesta por el ciudadano A.V.V.G, autorizando el cambio de sexo del demandante ${ }^{15}$.

Sobre el particular, la Defensoría del Pueblo afirma que la decisión del RENIEC afecta grave y principalmente el derecho a la Identidad de Género del demandante y contraviene la Constitución Política así como los estándares y las obligaciones internacionales asumidas por el Perú a consecuencia de los Tratados de Derechos Humanos que ha ratificado, por lo que resulta indispensable que la Segunda Sala Civil, confirme la resolución cuestionada, dado el tratamiento que este derecho viene recibiendo por tribunales e instancias internacionales así como en la jurisprudencia del Tribunal Constitucional y el Derecho Comparado.

En esa línea, la Defensoría del Pueblo, en el referido Informe recuerda que el Alto Comisionado de las Naciones Unidas para los Derechos Humanos (en adelante, Alto Comisionado) recomendó a los Estados emitir documentos que reflejen la identidad de género de las personas. Asimismo, recuerda que el Comité de Derechos Humanos ha mostrado especial inquietud por la renuencia de estos a no hacerlo, y por el contrario, ha saludado la aprobación de normas que permiten el cambio de nombre y sexo en los documentos.

Además, la Defensoría del Pueblo destaca que el Alto Comisionado ha señalado que el procedimiento para el cambio de los datos de identidad debe ser simple, de naturaleza administrativa, basarse en la autoidentificación y no requerir certificados médicos, cirugías, esterilizaciones o el divorcio como condiciones previas. No obstante, manifestó que a la espera de la legislación sobre la materia los Estados pueden realizar acciones para lograr dicho objetivo.

15 Es importante aclarar que la defensa jurídica de los intereses del Estado peruano está a cargo de los Procuradores Públicos, y que es el Consejo de Defensa Jurídica del Estado (CDJE), órgano adscrito al Ministerio de Justicia, el órgano colegiado encargado de dirigir y supervisar la labor de los mismos. Hago esta precisión porque en estricto el Procurador Público del RENIEC no depende funcionalmente ni responde ante el Jefe Nacional de la referida entidad. 
Por último, la Defensoría del Pueblo advierte que se deben respetar los derechos de las personas trans, incluido el derecho a la Identidad de Género, independientemente de que se hayan o no interpuesto acciones legales para lograr su reconocimiento. La Defensoría del Pueblo hace este último apunte pues considera justamente que la ausencia de este tipo de normas propicia un clima de discriminación y violencia contra las personas trans que puede empezar desde los primeros años de su vida tal como se advirtió en el Informe del Experto Independiente sobre la protección contra la violencia y la discriminación por motivos de orientación sexual o identidad de género referido en el Informe Defensorial.

En ese orden de ideas, al momento de evaluar la decisión del RENIEC, la Defensoría del Pueblo estimó necesario hacer hincapié en que en 1978, el Perú ratificó la Convención Americana de Derechos Humanos y en 1981 reconoció la competencia de la Comisión Interamericana de Derechos Humanos y de la Corte Interamericana de Derechos Humanos, de conformidad con los artículos $45^{\circ}$ y $62^{\circ}$ de la referida Convención, que de acuerdo al artículo $55^{\circ}$ de la Constitución Política y al Tribunal Constitucional, forma parte del derecho nacional y ostenta rango constitucional, según lo establecido en el Fundamento 13 de la Sentencia Nº 000007-2007-AI/TC.

Así pues, afirma la Defensoría del Pueblo, dado que el mandato de igualdad y no discriminación previsto en el artículo 2.2 de la Constitución Política, debe interpretarse de conformidad con la Declaración Universal de Derechos Humanos y con los tratados y acuerdos internacionales sobre las mismas materias ratificados por el Perú (por ejemplo, la Convención Americana de Derechos Humanos), tal como lo manda su Cuarta Disposición Final y Transitoria, antes ya mencionada, no es posible hacer una diferencia injustificada sobre la base de la Identidad de Género de una persona.

En consecuencia, subraya la Defensoría del Pueblo, dado que la Opinión Consultiva OC-24/2017 es de obligatorio cumplimiento para el Estado peruano, este debe modificar su legislación para reconocerla, es decir, permitir el cambio de nombre, sexo y otros datos u elementos en los documentos personales, como los certificados de nacimiento, el Documento Nacional de Identidad, el Pasaporte, entre otros.

\subsection{El Estado peruano y los Principios de Yogyakarta}

Al respecto, la Defensoría del Pueblo, en el Informe aludido en el punto precedente, recuerda que los Principios de Yogyakarta fueron aprobados por un grupo de expertos en derechos humanos durante un 
seminario que se llevó a cabo en noviembre de 2006, donde se discutió sobre los estándares internacionales mínimos que los Estados deben cumplir en materia de derechos humanos, Orientación Sexual e Identidad de Género, frente a la histórica y sistemática violación a los derechos humanos de las personas LGTBI.

Sobre el particular, la Defensoría del Pueblo advierte que en total, constan de 38 principios con recomendaciones dirigidas principalmente a los Estados. Pero toma especial interés por el tenor del Principio 3 "El derecho al reconocimiento de la personalidad jurídica", que prescribe que la Orientación Sexual o Identidad de Género de una persona es un elemento sustancial de su personalidad, dignidad y libertad. Por consiguiente, los Estados tienen que:

\section{(...)}

B. Adoptarán todas las medidas legislativas, administrativas y de cualquier otra índole que sean necesarias para respetar plenamente y reconocer legalmente el derecho de cada persona a la identidad de género que ella defina para sí;

C. Adoptarán todas las medidas legislativas, administrativas y de cualquier otra índole que sean necesarias a fin de asegurar que existan procedimientos mediante los cuales todos los documentos de identidad emitidos por el Estado que indican el género o el sexo de una persona -incluyendo certificados de nacimiento, pasaportes, registros electorales y otros documentos- reflejen la identidad de género profunda que la persona define por y para sí;

D. Garantizarán que tales procedimientos sean eficientes, justos y no discriminatorios y que respeten la dignidad y privacidad de la persona concernida.

$(\ldots)$

Como puede apreciarse, se trata de principios -sobre todo el Principio 3- que concuerdan con los estándares del Sistema Universal y Regional de Protección de Derechos Humanos en el sentido de reafirmar, según lo expone la Defensoría del Pueblo, que mientras el sexo o género se siga registrando, debe asegurarse un mecanismo rápido, transparente, y accesible para el reconocimiento legal de la Identidad de Género de una persona prescindiendo de intervenciones o diagnósticos médicos o psicológicos, límites de edad, condición económica o de salud, estado civil, opiniones de terceros, entre otros. 
Por último, es importante señalar que por su parte, la Defensoría del Pueblo ha sido enfática en ratificar que los Principios de Yogyakarta son una fuente de interpretación válida y necesaria que el Estado peruano debe observar al adoptar cualquier decisión, medida o norma que involucren los derechos de la población de las personas trans, más aún cuando la expresión y vivencias de sus orientaciones e identidades las coloca en una situación de vulnerabilidad que las hace merecedoras de una especial protección.

\section{CONCLUSIONES}

Por lo antes expuesto, considero necesario finalizar este trabajo que busca sentar las bases para la elaboración de una investigación más amplia, compartiendo cinco apuntes -a modo de conclusión- que explican cuál es el estado actual de la protección del derecho a la Identidad de Género de las personas trans en el ordenamiento jurídico peruano y hacia a dónde deberíamos apuntar en esta materia.

Primero,esimportanteseñalarquetomandoenconsideraciónelmandato establecido en las disposiciones jurídicas nacionales previamente citadas, referidas a la interpretación de los derechos fundamentales, el contenido de la mencionada OC 24/17, y lo señalado por el Tribunal Constitucional en la Sentencia $N^{\circ}$ 06040-2015-PA/TC, mediante la cual -como ya recordé- se garantiza el derecho de acceso a la justicia de las personas trans que deseen solicitar la modificación de sus datos en sus documentos de identidad, pues se reconoce la competencia de los jueces para tutelar el derecho a la identidad y a la personalidad jurídica de las personas trans, ya que se considera que "ya no existe ningún impedimento, ni legal, ni jurisprudencial, para garantizar estos derechos", quedando claro que no existe fundamento alguno para que los jueces peruanos denieguen las solicitudes de cambio de sexo y / o nombre de las personas trans, ya que ello supondría una violación al derecho a la Identidad de Género de estas personas.

Segundo, es necesario, por los argumentos expuestos por la Corte (también por el RENIEC y la Defensoría del Pueblo, respectivamente): "Aprobar una Ley de Identidad de Género que establezca un procedimiento administrativo a cargo del RENIEC para que las personas trans puedan cambiar su sexo y/o nombre en sus documentos de identidad, desjudicializando esta materia".

Tercero, de aprobarse esta Ley, el procedimiento administrativo previsto debería cumplir con las siguientes condiciones: 1) Debe estar enfocado a la adecuación integral de la identidad de género auto-percibida; 
2) Debe estar basado únicamente en el consentimiento libre e informado del solicitante sin que se exijan requisitos como las certificaciones médicas y /o psicológicas u otros que puedan resultar irrazonables o patologizantes; 3) Los procedimientos y los cambios, correcciones o adecuaciones en los registros deben ser confidenciales y los documentos de identidad no deben reflejar los cambios de la identidad de género; 4) Debe ser expedito y debe tender a la gratuidad; 5) No debe requerir que se lleven a cabo intervenciones quirúrgicas totales o parciales ni terapias hormonales, esterilizaciones o modificaciones corporales para sustentar el requerimiento, para otorgar lo solicitado o para probar la Identidad de Género que motiva dicho procedimiento, por cuanto podría ser contrario a la integridad personal, siguiendo la línea establecida por la Corte.

Cuarto, es perfectamente compatible con la Convención y con la Constitución Política, que el RENIEC, organismo constitucionalmente autónomo del Estado peruano, diseñe y apruebe un procedimiento administrativo para la tramitación de las solicitudes de cambio de sexo y/o nombre de las personas trans en defensa de su derecho a la Identidad de Género, el mismo que debería cumplir con las condiciones anotadas en el punto precedente, sin necesidad de que exista una Ley de Identidad de Género, aprobada por el Congreso de la República que regule esta materia, según lo establecido por la Corte.

En otras palabras, si el RENIEC decidiera aprobar el referido procedimiento administrativo, no estaría haciendo otra cosa que aplicar directamente la Convención y la Constitución Política, al amparo de la línea interpretativa sobre derechos fundamentales marcada tanto por la Corte como por nuestro Tribunal, respectivamente. Asimismo, si el RENIEC adoptara esta decisión también lo haría al amparo de lo expuesto por la Defensoría del Pueblo sobre la necesidad de entender a los Principios de Yogyakarta como una fuente de interpretación válida y necesaria que el Estado peruano debe observar al adoptar cualquier decisión, medida o norma que involucren los derechos de las personas trans.

Por último, siguiendo el razonamiento jurídico expuesto por la Defensoría del Pueblo, consideramos que los jueces y tribunales nacionales tienen el deber de realizar un control de convencionalidad sobre las normas y prácticas que rigen el proceso de cambio de nombre y sexo en el Perú, a la luz de la jurisprudencia de la Corte, así como de aplicar estándares internacionales en la materia, a fin de amparar la pretensión de aquellos ciudadanos, que como el señor A.V.V.G solicitan el cambio de nombre y sexo, respectivamente, para luego declarar fundadas este tipo de demandas, a 
pesar de la oposición de la Procuraduría Pública del RENIEC, o de cualquier otra entidad estatal y/o privada, pues como hemos podido apreciar, este tipo de posturas carecen hoy de todo fundamento constitucional y/o legal.

\section{REFERENCIAS}

Roa, Jorge Ernesto (2015). La función consultiva de la Corte Interamericana. Universidad Externado de Colombia. Bogóta.

Corte IDH (20 de Marzo 2013). Resolución de la Corte Interamericana de Derechos Humanos. Caso Gelman vs. Uruguay Supervisión de cumplimiento.

Fecha de recepción : : 31 de agosto de 2018

Fecha de aceptación : 20 de octubre 2018 